\title{
Análisis y comparación de las categorías e inventarios de la Ley de Patrimonio Histórico Español y las leyes de Patrimonio Cultural autonómicas del País Vasco y Canarias en el marco de la Convención de Granada
}

\author{
Luis Miguel Sanz Rodriguez, Antonio Eduardo Humero Martín, Fernando Casqueiro Barreiro
}

\begin{abstract}
Resumen: La Convención para la Salvaguarda del Patrimonio Arquitectónico de Europa, aprobada en 1985, constituye el núcleo doctrinal de la protección y conservación del Patrimonio Arquitectónico a nivel internacional. España ratifica la Convención en el año 1989, tras la aprobación de la Ley 16/1985 del Patrimonio Histórico Español con la que se adapta al marco jurídico internacional. En el contexto del estado autonómico, desde los años 90 todas las Comunidades Autónomas han aprobado gradualmente sus propias leyes de Patrimonio Cultural. El presente estudio analiza la ley estatal y las recién aprobadas leyes autonómicas del País Vasco y Canarias, centrado en dos aspectos en los que la Convención marca unas directrices: la definición de Patrimonio Arquitectónico y la identificación de los bienes objeto de protección.
\end{abstract}

Palabras clave: patrimonio arquitectónico, protección, legislación española, Convención de Granada

\section{Analysis and comparison of the categories and inventories of the Spanish Historical Heritage Law and the autonomous Cultural Heritage laws of the Basque County and Canary Islands in the framework of the Granada Convention}

\begin{abstract}
The Convention for the Protection of the Architectural Heritage of Europe, adopted in 1985, constitutes the doctrinal core of the protection and conservation of the Architectural Heritage at an international level. Spain ratifies the Convention in 1989, after the approval of Law 16/1985 of the Spanish Historical Heritage adhering to the international legal framework. In the context of the autonomous state, since the 1990s all the Autonomous Communities have gradually adopted their own Cultural Heritage laws. The present study analyses the State's law and the Autonomous laws of the Basque Country and Canary Islands, focusing on two of the aspects in which the Convention sets guidelines: the definition of Architectural Heritage and the identification of the assets subject to protection.
\end{abstract}

Keyword: architectural heritage, protection, Spanish legislation, Granada Convention

Análise e comparação das categorias e inventários da Lei de Património Histórico Espanhol e das leis de Património Cultural autónomo dos Países Bascos e Canários no âmbito da Convenção de Granada

Resumo: A Convenção para a Salvaguarda do Património Arquitetónico da Europa, aprovada em 1985, constitui o núcleo doutrinário da proteção e conservação do Património Arquitetónico a nível internacional. A Espanha ratifica a Convenção em 1989, após a aprovação da Lei 16/1985 sobre o Património Histórico Espanhol, com a qual se adapta ao quadro jurídico internacional. No contexto do estado autónomo, desde os anos 90, todas as comunidades autónomas passaram gradualmente as suas próprias leis de Património Cultural. $O$ presente estudo analisa a lei estadual e as leis autónomas recentemente aprovadas do País Basco e das Ilhas Canárias, concentrando-se em dois aspetos nos quais a Convenção estabelece diretrizes: a definição de Património Arquitetónico e a identificação dos bens sujeitos à proteção.

Palavras-chave: património arquitetónico, proteção, legislação espanhola, Convenção de Granada 


\section{Introducción}

La normativa internacional en materia de patrimonio cultural se ha desarrollado intensamente a lo largo del siglo XX y del XXI. Aunque no se trata de un listado exhaustivo de los documentos existentes a nivel internacional, en el cuadro que se adjunta en la página siguiente[Tabla 1] se resumen los principales documentos y convenios internacionales relacionados con la protección y salvaguarda del patrimonio arquitectónico y cultural que se han considerado relevantes para el presente estudio.

La Convención para la Salvaguarda del Patrimonio Arquitectónico de Europa, más conocida como Convención de Granada, fue aprobada por el Consejo de Europa en 1985 y fija las directrices a las que deben adecuarse las leyes nacionales de tutela del Patrimonio Histórico y Cultural de los países firmantes para recoger en las mismas los principios de la «conservación integrada».

La Convención, que constituye el núcleo doctrinal de la protección y conservación a nivel internacional, pretende, partiendo de un régimen de protección, integrar el Patrimonio Arquitectónico en el sistema socioeconómico actual, de modo que sea al mismo tiempo testimonio del pasado y un motor de desarrollo de las regiones.

Para ello, cada Estado signatario debe identificar los bienes a proteger elaborando inventarios nacionales y desarrollar procedimientos legales de protección de acuerdo con los criterios establecidos en la Convención. España ratifica la Convención en el año 1989, tras la aprobación de la Ley 16/1985 del Patrimonio Histórico Español, que desarrolla la disposición en materia de patrimonio contenida en el artículo 46 de la Constitución y con la que España se adapta al marco jurídico internacional.

Este artículo toma como referencia fundamental la Convención de Granada por dos motivos: 1) la legislación española, de ámbito estatal, vigente hoy en día sigue siendo la misma que cuando se ratificó dicha convención, a pesar de que España haya suscrito nuevos convenios; 2) dicha convención se refiere específicamente al patrimonio arquitectónico y sentó las bases fundamentales sobre identificación y categorización de los bienes culturales inmuebles, que son objeto de estudio en este artículo.

No obstante, el estudio también tiene en cuenta los documentos y convenios publicados tras la promulgación de la Convención de Granada. Entre ellos, cabe destacar la importancia de la Carta de Cracovia del año 2000, circunscrita a Europa, sobre los principios para la conservación y restauración del patrimonio construido. Mantiene el espíritu de la Carta de Venecia de 1964 y actualiza al tiempo presente, tras los cambios producidos en cuarenta años, los criterios en elámbitojurídico, cultural y tecnológico, para mejorar las medidas de salvaguardia del patrimonio, ofreciendo definiciones terminológicas para el entendimiento común y considerando el paisaje y el territorio como integrantes de la ciudad histórica. (Rivera Blanco, 2005: 405).

Adicionalmente, el marco jurídico-constitucional español se basa en un Estado descentralizado que se configura a través de las distintas autonomías que lo componen, de forma que todo el derecho sustantivo sobre el patrimonio cultural se estructura en torno a la dicotomía existente entre el Patrimonio Histórico Español, y los "Patrimonios Autonómicos", diferenciados, pero a la vez insertos en el primero (Azpeitia, 2016). En base al artículo 148.1 de la Constitución, que otorga competencias a las Comunidades Autónomas en «el patrimonio monumental de interés para la Comunidad Autónoma», desde los años 90 todas han promulgado gradualmente sus propias leyes de Patrimonio.

Por ello, para el presente estudio, además de la ley española de ámbito estatal y la Convención de Granada en la esfera internacional, se han seleccionado las dos leyes autonómicas de publicación más reciente:

- La Ley 11/2019, de 25 de abril, de Patrimonio Cultural de Canarias, que sustituye a la Ley 4/1999, de 15 de marzo, de Patrimonio Histórico de Canarias.

- La ley 6/2019, de 9 de mayo, de Patrimonio Cultural Vasco que sustituye a la Ley 7/1990, de 3 de julio, del Patrimonio Cultural Vasco. El País Vasco fue pionero en esta materia, siendo de las primeras comunidades autónomas en promulgar su propia ley.

Esta elección se ha tomado teniendo en cuenta que las dos leyes elegidas son las leyes autonómicas de segunda generación más actuales, ya que han sido promulgadas en 2019, por lo que se estudiará, dentro de los aspectos analizados, la potencial influencia de los documentos internacionales con relevancia en el ámbito de identificación y categorización de bienes posteriores a la Convención de Granada [1].

\section{Dispositivo experimental}

El presente estudio se centra en dos de los aspectos de la Convención de Granada y, sigue un análisis comparativo de las leyes citadas con el objetivo de: 1) detectar las principales similitudes y diferencias; 2) analizar su alineación con los preceptos de la Convención de Granada; 3) estudiar la influencia de los textos legislativos más recientes; 4) concluir sobre las implicaciones de la coexistencia de leyes estatales y autonómicas en materia de conservación del patrimonio arquitectónico. Los aspectos de la Convención de Granada estudiados son:

- La definición de Patrimonio Arquitectónico

- La identificación de los bienes objeto de protección 
Tabla 1.- Documentos y convenios internacionales

\begin{tabular}{|c|c|c|c|c|}
\hline Año & $\begin{array}{l}\text { Documentos } \\
\text { y convenios } \\
\text { internacionales }\end{array}$ & $\begin{array}{l}\text { Organismo } \\
\text { relacionado }\end{array}$ & Detalle & Relevancia \\
\hline 1964 & Carta de Venecia & $\begin{array}{l}\text { Expertos } \\
\text { internacionales }\end{array}$ & $\begin{array}{l}\text { Carta Internacional para la } \\
\text { Conservación y Restauración de } \\
\text { Monumentos y Sitios (II Congreso } \\
\text { Internacional de Arquitectos y } \\
\text { Técnicos en Monumentos Históricos). }\end{array}$ & $\begin{array}{l}\text { Supone la base fundamental de futuros documentos } \\
\text { internacionales sobre conservación y restauración. } \\
\text { ICOMOS fue fundado en 1965, como resultado de la } \\
\text { Carta de Venecia de } 1964 \text {. }\end{array}$ \\
\hline 1972 & $\begin{array}{l}\text { Convención de } \\
\text { París }\end{array}$ & UNESCO & $\begin{array}{l}\text { Convención sobre la Protección } \\
\text { del Patrimonio Mundial, Cultural y } \\
\text { Natural. }\end{array}$ & $\begin{array}{l}\text { Se crea un Comité intergubernamental de protección } \\
\text { del patrimonio cultural y natural y el Fondo para } \\
\text { protección del patrimonio mundial cultural y natural. }\end{array}$ \\
\hline 1976 & $\begin{array}{l}\text { Recomendación } \\
\text { de Varsovia y } \\
\text { Nairobi }\end{array}$ & UNESCO & $\begin{array}{l}\text { Recomendación sobre la salvaguarda } \\
\text { de los conjuntos históricos o } \\
\text { tradicionales. }\end{array}$ & $\begin{array}{l}\text { Define el conjunto histórico o tradicional, que sentará } \\
\text { las bases para la futura definición de paisaje urbano } \\
\text { histórico. }\end{array}$ \\
\hline 1985 & $\begin{array}{l}\text { Convención de } \\
\text { Granada }\end{array}$ & $\begin{array}{l}\text { Consejo de } \\
\text { Europa }\end{array}$ & $\begin{array}{l}\text { Convención para la Salvaguarda del } \\
\text { Patrimonio Arquitectónico de Europa. }\end{array}$ & $\begin{array}{l}\text { Marco fundamental en materia de Patrimonio } \\
\text { Arquitectónico en Europa, detallando la relevancia de } \\
\text { la identificación y categorización de bienes objeto de } \\
\text { protección. }\end{array}$ \\
\hline $\begin{array}{l}1986- \\
1987\end{array}$ & $\begin{array}{l}\text { Carta de Toledo } \\
\text { y Carta de } \\
\text { Washington }\end{array}$ & ICOMOS & $\begin{array}{l}\text { Carta Internacional para la } \\
\text { conservación de Ciudades Históricas } \\
\text { y Áreas Urbanas Históricas (ratificada } \\
\text { en VIII Asamblea General de ICOMOS). }\end{array}$ & $\begin{array}{l}\text { Complementaria de la Carta de Venecia de } 1964 \text {. } \\
\text { Incorporan un enfoque sistémico, entendiendo la } \\
\text { ciudad en su totalidad como una entidad histórica y } \\
\text { como una construcción social y dinámica que requiere } \\
\text { políticas coherentes de desarrollo económico y social } \\
\text { (Azkarate, Azpeitia, 2016: 310). }\end{array}$ \\
\hline 2000 & $\begin{array}{l}\text { Carta de } \\
\text { Cracovia }\end{array}$ & $\begin{array}{l}\text { Expertos } \\
\text { internacionales }\end{array}$ & $\begin{array}{l}\text { Principios para la conservación } \\
\text { y restauración del Patrimonio } \\
\text { construido. }\end{array}$ & $\begin{array}{l}\text { Actualización de la Carta de Venecia en base a los } \\
\text { avances internacionales en materia de conservación } \\
\text { del Patrimonio arquitectónico. Tiene como objetivo la } \\
\text { conservación del patrimonio arquitectónico, urbano y } \\
\text { paisajístico. }\end{array}$ \\
\hline 2000 & $\begin{array}{l}\text { Convenio } \\
\text { europeo del } \\
\text { paisaje }\end{array}$ & $\begin{array}{l}\text { Consejo de } \\
\text { Europa }\end{array}$ & $\begin{array}{l}\text { Convenio europeo que pretende } \\
\text { promover la protección, gestión y } \\
\text { ordenación de los paisajes europeos. }\end{array}$ & $\begin{array}{l}\text { Los conceptos de Patrimonio Cultural y Natural por } \\
\text { primera vez se fusionan en una visión integral del } \\
\text { paisaje. Ratificado por España en 2007. No obstante, } \\
\text { el Comité del Patrimonio Mundial (1992) adoptó } \\
\text { las Directrices Prácticas para la aplicación de la } \\
\text { Convención del Patrimonio Mundial, introduciendo ya } \\
\text { una nueva categoría de "Paisajes Culturales" (Azkarate, } \\
\text { Azpeitia, 2016: 310). }\end{array}$ \\
\hline 2003 & $\begin{array}{l}\text { Carta de Nizhny } \\
\text { Tagil }\end{array}$ & $\begin{array}{l}\text { Comité } \\
\text { Internacional } \\
\text { para la } \\
\text { Conservación } \\
\text { del Patrimonio } \\
\text { Industrial }\end{array}$ & Carta sobre el Patrimonio Industrial & $\begin{array}{l}\text { Basada en el espíritu de la Carta de Venecia, pone de } \\
\text { relieve la importancia del patrimonio industrial. }\end{array}$ \\
\hline 2005 & $\begin{array}{l}\text { Convenio de } \\
\text { Faro }\end{array}$ & $\begin{array}{l}\text { Consejo de } \\
\text { Europa }\end{array}$ & $\begin{array}{l}\text { Convenio sobre el valor del } \\
\text { patrimonio cultural para la sociedad }\end{array}$ & $\begin{array}{l}\text { Exige la creación de un marco que coloque el } \\
\text { patrimonio cultural en el centro de la atención social } \\
\text { y fortalezca el acceso público y la participación en el } \\
\text { patrimonio cultural. Ratificado por España en } 2018 \text {. }\end{array}$ \\
\hline 2005 & $\begin{array}{l}\text { Memorándum } \\
\text { de Viena }\end{array}$ & $\begin{array}{l}\text { UNESCO- } \\
\text { ICOMOS }\end{array}$ & $\begin{array}{l}\text { Patrimonio Mundial y la Arquitectura } \\
\text { Contemporánea. Gestión del Paisaje } \\
\text { Histórico Urbano. }\end{array}$ & $\begin{array}{l}\text { Aparece el concepto de Paisaje Urbano Histórico } \\
\text { (la definición fue redactada definitivamente en } \\
\text { 2010). Hace referencia explícita a la arquitectura } \\
\text { contemporánea. }\end{array}$ \\
\hline 2008 & $\begin{array}{l}\text { Carta de } \\
\text { Itinerarios } \\
\text { Culturales }\end{array}$ & ICOMOS & Carta de Itinerarios Culturales & $\begin{array}{l}\text { Destaca el reconocimiento de los Itinerarios Culturales } \\
\text { como nueva categoría patrimonial. }\end{array}$ \\
\hline 2011 & $\begin{array}{l}\text { Recomendación } \\
\text { de París }\end{array}$ & UNESCO & $\begin{array}{l}\text { Recomendación sobre el Paisaje } \\
\text { Urbano Histórico }\end{array}$ & $\begin{array}{l}\text { Se concluye la definición de Paisaje Urbano Histórico } \\
\text { que incluye su medio urbanizado tanto histórico como } \\
\text { contemporáneo }\end{array}$ \\
\hline 2018 & $\begin{array}{l}\text { Declaración de } \\
\text { Davos }\end{array}$ & $\begin{array}{l}\text { Consejo de } \\
\text { Europa y } \\
\text { Convenio } \\
\text { Cultural } \\
\text { Europeo }\end{array}$ & $\begin{array}{l}\text { Hacia una Baukultur de alta calidad } \\
\text { para Europa. Consejo de Europa, } \\
\text { Participan asimismo UNESCO, } \\
\text { ICCROM, ICOMOS, Comisión Europea, } \\
\text { Consejo de Arquitectos de Europa, } \\
\text { Consejo de Europa de Urbanistas y } \\
\text { Europa Nostra. }\end{array}$ & $\begin{array}{l}\text { El concepto de Baukultur que como aspecto de } \\
\text { identidad cultural y diversidad abarca de manera } \\
\text { integral todas las actividades humanas que cambian el } \\
\text { entorno construido }\end{array}$ \\
\hline
\end{tabular}


Las leyes objeto del presente estudio están concebidas para la protección de todo el patrimonio cultural, mientras que el ámbito de aplicación de la Convención de Granada es el patrimonio arquitectónico. Por ello, el análisis se circunscribirá a dicho ámbito.

\section{—Definición del patrimonio arquitectónico}

En la tabla 2 se muestran las diversas categorías, con el máximo grado de protección, en que se clasifican los bienes inmuebles que constituyen el patrimonio arquitectónico según cada una de las leyes estudiadas. [Tabla 2]

\section{- Identificación de los bienes objeto de protección}

El artículo segundo de la Convención de Granada establece la obligatoriedad, por parte de los Estados firmantes, de realizar un inventario de los bienes inmuebles susceptibles de protección con el fin de identificarlos para hacer efectiva dicha protección. Con esa finalidad las leyes estudiadas establecen:

- La ley 16/1985 de Patrimonio Histórico Español establece dos inventarios:

- El Registro General de Bienes de Interés Cultural, donde se incluyen bienes tanto muebles como inmuebles con un mayor grado de protección.

- El Inventario General contiene los bienes muebles de singular relevancia no declarados de interés cultural.

-La Ley 6/2019, de 9 de mayo, de Patrimonio Cultural Vasco establece dos inventarios:

- El Registro de la CAPV del Patrimonio Cultural Vasco, en el que se inscribirán los bienes de protección especial y de protección media.

- El Registro de la CAPV de Bienes Culturales de Protección Básica que incluye los bienes inmuebles

Tabla 2.- Categorías de bienes inmuebles y valores a proteger

\begin{tabular}{|c|c|c|c|}
\hline Convención de Granada & Ley $16 / 1985$ Estatal & Ley $11 / 2019$ de Canarias & Ley 6/2019 País Vasco \\
\hline \multicolumn{4}{|c|}{ CATEGORÍAS DE BIENES INMUEBLES [2] } \\
\hline $\begin{array}{c}\text { Monumento } \\
\text { Conjunto arquitectónico } \\
\text { Sitio }\end{array}$ & $\begin{array}{c}\text { Monumento } \\
\text { Conjunto Histórico } \\
\text { Sitio Histórico } \\
\text { Jardín Histórico }\end{array}$ & $\begin{array}{c}\text { Monumento } \\
\text { Conjunto Histórico } \\
\text { Sitio Histórico } \\
\text { Jardín Histórico } \\
\text { Paisaje cultural }\end{array}$ & $\begin{array}{c}\text { Monumento } \\
\text { Conjunto monumental } \\
\text { Espacio cultural } \\
\text { Jardín Histórico } \\
\text { - } \\
\text { Itinerario cultural }\end{array}$ \\
\hline \multicolumn{4}{|c|}{ VALOR O INTERÉS } \\
\hline $\begin{array}{c}\text { Histórico } \\
\text { Arqueológico } \\
\text { Artístico } \\
\text { Científico } \\
\text { Social } \\
\text { Técnico }\end{array}$ & $\begin{array}{c}\text { Histórico } \\
\text { Arqueológico } \\
\text { Artístico } \\
\text { Científico } \\
\text { - } \\
\text { Técnico } \\
\text { Paleontológico } \\
\text { Etnográfico }\end{array}$ & $\begin{array}{c}\text { Histórico } \\
\text { Arqueológico } \\
\text { Artístico } \\
\text { Científico } \\
\text { - } \\
\text { Técnico } \\
\text { - } \\
\text { Etnográfico } \\
\text { Industrial } \\
\text { Arquitectónico } \\
\text { - } \\
\text { - } \\
\text { Paisajístico } \\
\text { Otra naturaleza cultural }\end{array}$ & $\begin{array}{c}\text { Histórico } \\
\text { Arqueológico } \\
\text { Artístico } \\
\text { Científico } \\
\text { - } \\
\text { Paleontológico } \\
\text {-- } \\
\text { Industrial } \\
\text { Arquitectónico } \\
\text { Etnológico } \\
\text { Antropológico } \\
\text { Paisajístico } \\
\text { Otra naturaleza cultural }\end{array}$ \\
\hline
\end{tabular}


de los catálogos del planeamiento urbanístico municipal (salvo en el caso de aquellos bienes que estén incluidos en el Registro de la CAPV del Patrimonio Cultural Vasco).

-La Ley 11/2019, de 25 de abril, de Patrimonio Cultural de Canarias crea tres inventarios, en alguno de los cuales deberán incluirse los bienes integrantes del patrimonio cultural de Canarias para su protección:

- Registro de Bienes de Interés Cultural.

- Catálogo insular de bienes patrimoniales culturales.

- Catálogo municipal de bienes patrimoniales culturales.

En cuanto al acceso a los inventarios, las leyes autonómicas establecen claramente en su articulado que la información contenida en los mismos será accesible a los ciudadanos, aunque establezca determinadas limitaciones derivadas de la seguridad y el orden público, la intimidad de las personas o los secretos comerciales y científicos. En cambio, la ley estatal y sus reales decretos de desarrollo
(Real Decreto 111/1986 y Real Decreto 64/1994) estipulan la información, así como el régimen de visitas fijado en el artículo 13.2 de la Ley 16/1985, que debe quedar reflejada en el Registro General y fijan que «será preciso el consentimiento expreso del titular para la consulta pública de la situación jurídica y el valor de los bienes inscritos y su ubicación en el caso de bienes muebles». De esta limitación, se deriva que el resto de información contenida en el Registro General y relevante desde un punto de vista cultural debería ser accesible.

Consultadas las webs de cada uno de los organismos competentes que gestionan los inventarios de Bienes de Interés Cultural, se ha elaborado el cuadro que se adjunta a continuación [Tabla 3], en el que se resume la información disponible en la red de cada uno de los inventarios estudiados.

Cabe destacar que la web del Ministerio de Cultura facilita la fecha del BOE de la declaración, pero no adjunta el decreto de declaración. Asimismo, los Bienes de Interés

Tabla 3.- Información disponible en webs públicas

\begin{tabular}{|c|c|c|}
\hline $\begin{array}{c}\text { Registro General de Bienes de Interés } \\
\text { Cultural (Estatal) }\end{array}$ & $\begin{array}{l}\text { Registro de Bienes de Interés Cultural } \\
\text { de Canarias }\end{array}$ & $\begin{array}{c}\text { Registro de la CAPV del Patrimonio } \\
\text { Cultural Vasco }\end{array}$ \\
\hline \multicolumn{3}{|c|}{ INFORMACIÓN DISPONIBLE A TRAVÉS DE LAS RESPECTIVAS PÁGINAS WEB } \\
\hline $\begin{array}{l}\text { Localización } \\
\text { Comunidad Autónoma }\end{array}$ & Localización & Localización \\
\hline Provincia & Isla & Provincia \\
\hline Municipio & Municipio & Municipio \\
\hline Categoría & Categoría & Categoría \\
\hline Fecha de declaración & - & - \\
\hline Fecha Boletín Declaración & - & - \\
\hline- & Decreto de declaración & Decreto de declaración \\
\hline Código & - & - \\
\hline Registro & - & - \\
\hline Matiz & - & - \\
\hline- & Breve descripción & Breve descripción \\
\hline- & Fotografía & Fotografía \\
\hline- & - & Periodo general \\
\hline- & - & Siglo \\
\hline- & - & Estilo \\
\hline- & - & Grado de protección \\
\hline- & - & No ficha \\
\hline - & - & Tipología \\
\hline
\end{tabular}


Cultural cuentan con un código donde los dos primeros dígitos indican el tipo de bien y los siete siguientes son el código identificativo del mismo.

\section{Discusión de resultados}

Del análisis comparativo desarrollado se deduce que si bien la legislación española, tanto a nivel nacional como autonómico, cumple los preceptos recogidos por la Convención de Granada y las actualizaciones incorporadas por otros documentos dentro de los aspectos analizados, se han observado diferencias relevantes que ponen de manifiesto un tratamiento sustancialmente distinto desde las autonomías y desde el gobierno central de aspectos relativos a la identificación e inventariado del patrimonio arquitectónico.

\section{—Definición del patrimonio arquitectónico}

Como se recoge en el epígrafe anterior [Tabla 2], las tres leyes analizadas recogen los valores contenidos en la Convención, pero las leyes autonómicas amplían su alcance para recoger nuevos valores, asumiéndose así que el concepto mismo de patrimonio está en permanente construcción y que los elementos que lo configuran forman un conjunto susceptible de modificación y abierto a nuevas incorporaciones. Muestra de ello es la inclusión de:

- El valor industrial como parte del patrimonio cultural, referente a los procesos y a la tecnología, cuya definición, catalogación y protección se recoge en la Carta de Nizhny Tagil sobre Patrimonio Industrial de 2003.

- El valor paisajístico como incorporación de las directrices recogidas en el Convenio Europeo del Paisaje del 2000.

- El valor arquitectónico, ya recogido en la ley canaria anterior y que en el caso de la ley vasca se incorpora en su última versión, pero se elimina el valor urbanístico que aparecía en su predecesora.

Asimismo, en ambas leyes autonómicas, después de la especificación de valores que debe tener el patrimonio cultural para ser digno de protección, se añade «cualquier otra naturaleza cultural» previendo la evolución del concepto de patrimonio, pero implicando también, dada la vaguedad en su redacción, que los verdaderos valores dignos de protección queden potencialmente diluidos y que los bienes más importantes no sean objeto de la suficiente protección.

Por otro lado, se observa una especialización en los valores a proteger, al no hacerse referencia al valor social de la Convención de Granada, pero sí a otros más específicos como el valor paleontológico, etnográfico, etnológico y antropológico.

En cuanto a las categorías, si bien puede considerarse que se ajustan a lo establecido internacionalmente, aunque la nomenclatura y definición no sea exactamente la misma, es importante hacer varias consideraciones:

- En la definición de Monumento, la redacción dada en la ley estatal y la canaria es prácticamente idéntica, mientras que la del País Vasco, aunque incluya lo establecido en las otras dos, es más genérica y abierta como ocurría también en su predecesora, la ley 7/1990, de 3 de julio, del Patrimonio Cultural Vasco en la que un monumento podía ser tanto un bien mueble como inmueble.

- En cuanto al Jardín Histórico, hay que destacar que esta categoría no existe en la Convención de Granada con esta nomenclatura, si bien el concepto recogido en las leyes estudiadas se ajusta al de Sitio de la Convención. Como en el caso anterior, la ley estatal y la de Canarias es muy similar añadiendo esta última el valor artístico, mientras que la ley vasca es muy ambigua en su definición.

- En referencia al concepto de Conjunto Histórico/ Monumental, las tres leyes recogen la misma idea, en este caso de manera mucho más clara que en los casos anteriores y cabe destacar cómo la ley del País Vasco ha clarificado la definición respecto a la ley anterior en la que un conjunto monumental podía estar integrado por bienes muebles o inmuebles.

-Dado que las leyes españolas, tanto estatal como autonómicas, adaptan el concepto de Sitio de la Convención a la categoría de Jardín Histórico, la idea de Sitio Histórico recogido en la legislación española está vinculada a acontecimientos del pasado, tradiciones o creaciones culturales más que al patrimonio arquitectónico.

- Por último, es importante citar la aparición de nuevas categorías en las leyes autonómicas de patrimonio, que, si bien no se circunscriben al ámbito arquitectónico, demuestran el avance producido a lo largo del tiempo en la propia definición de patrimonio cultural para su mejor comprensión y estudio. Muestra de ello, la ley del País Vasco contempla el Itinerario Cultural, concepto recogido en la Carta de Itinerarios Culturales de ICOMOS ratificada en 2008 y la ley canaria incluye tanto el sitio industrial como el paisaje cultural, recogido en el Convenio Europeo del Paisaje del 2000. No obstante, debe garantizarse que las definiciones de las nuevas categorías queden perfectamente perfiladas (Amoedo-Souto, 2017: 91;140), dado que un enunciado generalista y difuso, como el dado para los Paisajes Urbanos Históricos en el Memorándum de Viena o la Recomendación de París de 2011, puede conducir, imperceptiblemente, a una desregulación de los criterios de protección y conservación del patrimonio urbano (Azkarate, Azpeitia, 2016: 324). 


\section{Identificación de los bienes objeto de protección}

En los inventarios creados por cada una de las leyes, si bien cumplen el mandato de la Convención, se observa una gran diferencia en el nivel de información proporcionada por la ley estatal y las leyes autonómicas. La información proporcionada por el Registro General del Ministerio de Cultura no supone un verdadero valor añadido para el ciudadano de a pie, al no incluir ni una breve descripción, ni el Decreto de declaración que podría proporcionar esa información. Además, únicamente recoge los Bienes de Interés Cultural. De esta manera, los bienes que no tengan un interés especialmente notable no quedan inscritos en el inventario nacional, aunque posteriormente estén en los Catálogos de los municipios. Esto es así a pesar de que, como se apuntó en el epígrafe anterior, no existe una limitación legal que impida que, a nivel nacional, la información relacionada con los valores por los que un bien es digno de protección no pueda ser accesible para los ciudadanos a través de la red (datos recogidos en la declaración de Bien de Interés Cultural tal como establece el Real Decreto 111/1986).

Por otra parte, el desarrollo de las leyes autonómicas ha hecho que la declaración de los bienes merecedores de protección y, por tanto, su catalogación, la hagan fundamentalmente las Comunidades Autónomas (Alegre Ávila, 1991: 618). No obstante, deben trasladar al Registro General las inscripciones y restantes anotaciones registrales a efectos de constancia general (Real Decreto $111,1986)$.

De las leyes estudiadas, el inventario más completo que puede consultarse a través de la red es el del Departamento de Cultura y Política Lingüística del País Vasco que además de la localización y una descripción, incorpora el grado de protección, estilo etc. No obstante, en la web de la Consejería de Turismo, Cultura y Deportes de Canarias, al igual que en la del País Vasco, se puede descargar el decreto de declaración del bien, a través del cual se tiene acceso tanto a la información histórica del bien como a su delimitación geográfica.

Además, en ninguno de los tres casos, se ha conseguido obtener una tabla que resuma el número de bienes y su categorización en los inventarios del Estado y de cada Comunidad Autónoma, lo que permitiría tener un orden de magnitud del patrimonio arquitectónico existente. No obstante, a través del Anuario de Estadísticas Culturales 2018 del Ministerio de Cultura, se sabe que en el año 2017 el número de bienes inmuebles inscritos como Bienes de Interés Cultural (BIC) ascendió a 17.579, lo que supone un aumento del $0,7 \%$ respecto a 2016. De ellos, 1.894 fueron bienes incoados y 15.685 bienes declarados (MCD, 2018). Por otro lado, hay que destacar el hecho de que a pesar de que cada Comunidad Autónoma establezca sus propias categorías, el Registro General dependiente del Ministerio de Cultura se convierte en una única base de datos en la que quedan recogidos todos los Bienes de
Interés Cultural de España y en la que se les asigna un código de acuerdo a las categorías establecidas en la ley $16 / 1985$, por lo que la multiplicidad de categorías a nivel autonómico supone un impedimento a la hora de generar una base de datos global del patrimonio cultural español.

\section{Conclusiones}

Las principales conclusiones del presente estudio pueden resumirse en los siguientes epígrafes:

\section{-Cumplimiento de convenios internacionales}

-La legislación española se ajusta a la normativa jurídica internacional en materia de categorización e inventariado de los bienes inmuebles pertenecientes al patrimonio arquitectónico.

-El desarrollo de las leyes autonómicas de protección del patrimonio supone que la política en esta materia ha dejado de ser meramente estatal y por tanto unificada y unitaria, como demuestra la existencia de distintas categorías de protección que establecen cada una.

\section{- La evolución del concepto de patrimonio y la definición de nuevas categorías}

- A medida que se promulgan nuevas leyes como resultado de la evolución del concepto de patrimonio cultural recogido en diversos documentos y convenios internacionales, aparecen nuevas categorías cada vez más amplias en su concepción. Si bien la aparición de nuevas figuras de patrimonio cultural supone un avance en la comprensión del pasado, el hecho de que sean cada vez más amplias y con definiciones difusas y generalistas en su concepción puede llegar a poner en riesgo la protección del patrimonio arquitectónico.

-Al estudiarse las leyes autonómicas de aprobación más reciente, se observa una especialización cada vez mayor en los valores $y$, por lo tanto, en los tipos de patrimonio a proteger. Esta especialización, si bien es positiva para conseguir un mayor conocimiento del patrimonio arquitectónico, puede desembocar en una banalización del propio concepto. En definitiva, las leyes estudiadas tienen como principal objetivo proteger lo más relevante y sobresaliente de nuestra cultura.

\section{- Inventarios y acceso público a la información}

- El contenido y formato de la información disponible en los medios de difusión oficiales (páginas web) no están normalizados, aunque es de naturaleza y alcance similar en las dos leyes autonómicas estudiadas. Sin embargo, 
el hecho de que no haya una comunicación directa desde el Ministerio de Cultura a las distintas consejerías responsables de los inventarios autonómicos no facilita el acceso a los ciudadanos. Sería conveniente y, sin duda, haría más fácil el acceso a esta valiosa información el que los contenidos del Ministerio y las distintas Consejerías fuera de la misma naturaleza y alcance, así como que existiera una mutua redirección de las búsquedas, desde el Ministerio hacia las Consejerías y viceversa.

- La catalogación de los Bienes de Interés Cultural y la gestión de los inventarios por parte de las Comunidades Autónomas facilita que estos estén actualizados y sean más accesibles a los ciudadanos por su mayor proximidad, sin embargo, la multiplicidad de categorías puede acabar llevando el sistema a una ineficiencia indeseable.

- Coexistencia de acuerdos supranacionales, leyes estatales y autonómicas en materia de protección del patrimonio

-La coexistencia de categorías estatales y autonómicas, sumadas a las definidas internacionalmente por los convenios y cartas, puede no redundar en una mejora de la protección del patrimonio arquitectónico, a pesar de que todas ellas tengan un mismo núcleo doctrinal. Por ello, sería deseable aclarar los ámbitos de competencias. Ese "núcleo doctrinal" parece bien definido y de forma precisa y flexible en los acuerdos internacionales. Las "categorías y criterios de valor" podrían estar definidos en la legislación nacional y ser matizadas autonómicamente si fuese necesario. Las Comunidades Autónomas seguirían siendo las responsables de la catalogación y gestión de los inventarios, dado que esa gestión descentralizada y cercana al ciudadano se ha demostrado mucho más atenta y eficaz. Con ello, no se plantea una recentralización, sino una simplificación y optimización de los recursos intelectuales y financieros disponibles para una mejor protección del patrimonio arquitectónico.

\section{Notas}

[1] El presente estudio forma parte de un trabajo más amplio que incluye el análisis pormenorizado de todas las leyes autonómicas en materia de Patrimonio Cultural.

[2] Solo se han incluido las categorías de bienes relacionados con el patrimonio arquitectónico.

\section{Bibliografía}

- Artículos

AZPEITIA SANTANDER, A. (2016) "Patrimonio y cultura. El concepto de patrimonio cultural en la normativa vasca" Revista de la Facultad de Ciencias Sociales y Jurídicas de Elche, Volumen 1 Número 11: 369-389

AZKARATE, A y AZPEITIA, A. (2016) “Paisajes Urbanos Históricos. ¿Paradigma o subterfugio?" Alla ricerca di un passato complesso Contributi in onore di Gian Pietro Brogiolo per il suo settantesimo compleanno. 219-238

AMOEDO-SOUTO, C. (2017) "La ley 5/2016, de 4 de mayo, de patrimonio cultural de Galicia: una ley de baja calidad para un nuevo ciclo de desarrollismo" Revista Patrimonio Cultural y Derecho, número 21: 91-146

\section{-Congresos}

ALEGRE ÁVILA, J.M. (1991). “El ordenamiento estatal del Patrimonio Histórico Español: Principios y bases de su Régimen Jurídico" Seminario de Derecho Administrativo, Cantabria: Universidad de Cantabria.

RIVERA BLANCO, J. (2005). “Nuevas tendencias de la restauración monumental. De la Carta de Venecia a la Carta de Cracovia". En 2 Seminário A Intervenção no Património. Práticas de Conservação e Reabilitação, realizado na Faculdade de Engenharia da Universidade do Porto. Volume: 1.

\section{-Legislación}

BOE (1982) Instrumento de aceptación de 18 de marzo de 1982, de la Convención sobre la Protección del Patrimonio Mundial, Cultural y Natural, hecha en París el 23 de noviembre de 1972. Núm. 156, 17883-17887. https://www.boe.es/boe/ dias/1982/07/01/pdfs/A17883-17887.pdf

BOE (1985) Ley 16/1985, de 25 de junio, del Patrimonio Histórico Español. Núm. 155, 20342-20352. https://www.boe.es/boe/ dias/1985/06/29/pdfs/A20342-20352.pdf

BOE (1986) Real Decreto 111/1986, de 10 de enero, de desarrollo parcial de la Ley 16/1985, de 25 de junio de Patrimonio Histórico Español. Núm. 24, 3815-3831 https://www.boe.es/boe/ dias/1986/01/28/pdfs/A03815-03831.pdf

BOE (1989) Instrumento de Ratificación del Convenio para la Salvaguarda del Patrimonio Arquitectónico de Europa, hecho en Granada el 3 de octubre de 1985. Núm. 155, 20472-20475. https:// www.boe.es/boe/dias/1989/06/30/pdfs/A20472-20475.pdf

BOE (1994) Real Decreto 64/1994, de 21 de enero, por el que se modifica el Real Decreto 111/1986, de 10 de enero, de desarrollo parcial de la Ley 16/1985, de 25 de junio, del Patrimonio Histórico Español. Núm. 52, 6780-6785 https://www.boe.es/ boe/dias/1994/03/02/pdfs/A06780-06785.pdf

BOE (2012) Ley 7/1990, de 3 de julio, de Patrimonio Cultural Vasco. Núm. 51, 17498-17526. https://www.boe.es/buscar/ pdf/2012/BOE-A-2012-2861-consolidado.pdf 
BOE (2008) Instrumento de Ratificación del Convenio Europeo del Paisaje, hecho en Florencia el 20 de octubre de 2000. Núm. 31, 6259-6263. https://www.boe.es/boe/dias/2008/02/05/pdfs/ A06259-06263.pdf

BOE (2019) Ley 11/2019, de 25 de abril, de Patrimonio Cultural de Canarias. Núm. 140, 61264- 61338. https://www.boe.es/boe/ dias/2019/06/12/pdfs/BOE-A-2019-8707.pdf

BOE (2019) Ley 6/2019, de 9 de mayo, de Patrimonio Cultural Vasco. Núm. 128, 56452- 56492 https://www.boe.es/eli/espv/l/2019/05/09/6/dof/spa/pdf

-Cartas, recomendaciones internacionales y otros documentos de referencia

CONSEJO DE EUROPA (2005) Convenio sobre el valor del patrimonio cultural para la sociedad. Conocido generalmente como Convenio de Faro. https://rm.coe.int/16806a18d3

ICOMOS (1987): Carta internacional sobre la salvaguarda de las ciudades históricas. Conocida generalmente como Carta de Washington. http://www.international.icomos.org/towns sp.htm

TICCIH (2003): Carta de Nizhny Tagil sobre el Patrimonio Industrial. https://www.icomos.org/18thapril/2006/nizhnytagil-charter-sp.pdf

UNESCO (1976): Recomendación sobre la salvaguarda de los conjuntos históricos o tradicionales y su papel en la vida contemporánea. Conocida generalmente como Recomendación de Nairobi. http://portal.unesco.org/es/ev.php$\underline{R L} I D=13133 \&$ URL DO=DO TOPIC\&URL SECTION=201.html

UNESCO (2000) Principios para la conservación y restauración del patrimonio construido. Conocidos generalmente como Carta de Cracovia. https://en.unesco.org/sites/default/files/ guatemala carta cracovia 2000 spa orof.pdf

UNESCO (2005) Memorándum de Viena sobre el Patrimonio Mundial y la Arquitectura Contemporánea. Gestión del Paisaje Histórico Urbano. http://whc.unesco.org/archive/2005/whc0515ga-inf7e.pdfICOMOS (2008) Carta de Itinerarios Culturales. https://www.icomos.org/images/DOCUMENTS/Charters/ culturalroutes sp.pdf

UNESCO (2011) RECOMENDACIÓN SOBRE EL PAISAJE URBANO HISTÓRICO. Conocida generalmente como Recomendación de París. https://whc.unesco.org/uploads/activities/documents/ activity-638-100.pdf

MINISTERIO DE EDUCACIÓN, CULTURA Y DEPORTE (2018) Anuario de Estadísticas Culturales. http://www.culturaydeporte. gob.es/dam/jcr:f818fa71-6313-468b-9db1-6a44d4fbd461/ principales-resultados-2018.pdf

\section{Autor/es}

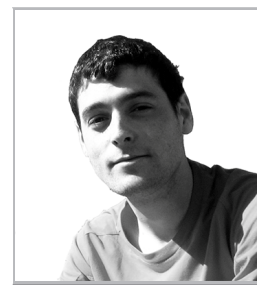

\begin{tabular}{l}
\hline Luis Miguel Sanz Rodriguez \\
Im.sanz@alumnos.upm.es \\
Escuela Técnica Superior de Arquitectura de \\
Madrid (ETSAM), Universidad Politécnica de \\
Madrid (UPM), España
\end{tabular}

Arquitecto por la Escuela Técnica Superior de Arquitectura (ETSAM) de la Universidad Politécnica de Madrid (UPM), España. Actualmente, se encuentra desarrollando el doctorado en la Universidad Politécnica de Madrid en el ámbito de la protección del patrimonio arquitectónico desde una perspectiva legislativa. Desde marzo de 2015, su experiencia profesional se ha desarrollado en el estudio de arquitectura PRODIARQ Gelabert y Asociados centrado especialmente en el campo de la rehabilitación de edificios y en informes periciales. Desde 2014 participa de forma activa en un proyecto de investigación sobre vivienda colectiva del arquitecto Mies van der Rohe, dentro del grupo de investigación ARKRIT de la Escuela Técnica Superior de Arquitectura de Madrid, Universidad Politécnica de Madrid.

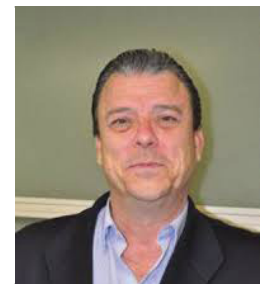

Antonio Eduardo Humero Martín

a.humero@upm.es

Escuela Técnica Superior de Arquitectura de Madrid (ETSAM), Universidad Politécnica de Madrid (UPM), España

Dr. Arquitecto desde el año 1997. Profesor Titular de la Universidad Politécnica de Madrid. Departamento de Construcción y Tecnología Arquitectónicas de la Escuela Técnica Superior de Arquitectura de Madrid. Director de diversos másteres, cursos de especialización y de la Cátedra Universidad-Empresa de Valoraciones de la Universidad Politécnica de Madrid, durante seis años. Investigador de los grupos de investigación «Regulación y Análisis Económico del Proceso Edificatorio» y «Técnicas Innovadoras y Sostenibles en la Edificación» del Área de Conocimiento de Construcciones Arquitectónicas de la Universidad Politécnica de Madrid. Autor de más de 100 publicaciones, en revistas indexadas, libros de autoría propia y compartida, capítulos de libros y contribuciones a congresos internacionales y nacionales, en editoriales de reconocido prestigio: Thomson Reuters Aranzadi, Dykinson, Wolters Kluwer, etc. Director de más de 100 proyectos de investigación de la Universidad Politécnica de Madrid, pertenecientes a las especialidades de patología edificatoria y responsabilidades en la construcción, urbanismo y ordenación del territorio y valoraciones expropiatorias y urbanísticas. Director de más de 10 tesis doctorales. Profesor invitado en universidades e instituciones oficiales y privadas de ámbito nacional e internacional (Argentina, Chile, Colombia, Panamá, etc.). Miembro de tribunales de oposición de ámbito nacional y local y de comisiones evaluadoras y científicas. 


Fernando Casqueiro Barreiro
fernando.casqueiro@upm.es
Escuela Técnica Superior de Arquitectura de
Madrid (ETSAM), Universidad Politécnica de
Madrid (UPM), España

Arquitecto y doctor por la ETSAM-UPM. Premio Extraordinario de Tesis Doctorales por la UPM, en 2002. Ha compatibilizado su actividad profesional con la académica y la investigadora. La mayor parte de su actividad profesional la ha desarrollado mediante encargos obtenidos en concursos públicos, internacionales, nacionales y restringidos (ganador en 33 ocasiones). Su obra ha sido expuesta en Santiago de Compostela, Stuttgart, París, Oporto, Zurich y Madrid.Es Profesor de "Proyectos Arquitectónicos" en la ETSAM_UPM desde 1991 hasta la actualidad.Miembro fundador del Grupo Consolidado de Investigación AKRIT (http://arkrit.dpaetsam.com/) y director de varios proyectos de investigación financiados por el Departamento de Proyectos de la ETSAM y por el Ministerio de Ciencia e Investigación. Autor de más de 40 artículos especializados y de divulgación. Autor de los libros: El Pabellón de Cristal de Madrid, Adenda a Arquitectura y Verdad, La Estación Marítima de Denia, Canon de Centros Escolares del Siglo XX.

Artículo enviado el 03/03/2019 Artículo aceptado el 07/11/2019 